\title{
Enough Is Enough! When Identification No Longer Prevents Negative Corporate Associations
}

\author{
Sabine A. Einwiller ${ }^{1}$ \\ University of Applied Sciences Northwestern Switzerland
}

Alexander Fedorikhin

Indiana University

\author{
Allison R. Johnson \\ Queen's University \\ Michael A. Kamins \\ University of Southern California
}

\begin{abstract}
Negative publicity has the potential to create negative corporate associations. However, consumers' identification with a company might moderate the extent of this effect. This article examines the impact of consumer-company identification on reactions to variable levels of negative publicity about a company. Exposing consumers who had strong identification with a company to moderately negative publicity was found to result in less negative corporate associations than for consumers who had relatively weak identification. In contrast, consumers'levels of identification did not affect reactions to extremely negative information, resulting in equally negative corporate associations for those with strong versus weak consumer-company identification. Thus, strong identification mitigates the effects of moderately negative publicity but does not attenuate the effects of extremely negative publicity. Consumers' perceptions of and thoughts regarding negative information about a company partially mediated the effect of identification on attitudes and behavioral intentions.
\end{abstract}

Keywords: consumer-company identification; corporate associations; negative publicity

\footnotetext{
Journal of the Academy of Marketing Science.

Volume 34, No. 2, pages 185-194.

DOI: $10.1177 / 0092070305284983$

Copyright $\odot 2006$ by Academy of Marketing Science.
}

In the first 4 years of the twenty-first century, we experienced an approximately 15 percent increase in negative business news coverage compared with coverage in the 1990s (Institute for Crisis Management 2004). Although major offenses by companies such as Enron, WorldCom, Arthur Anderson, and Tyco drove this trend, less sensational cases of mismanagement or underperformance have also been frequently covered.

How consumers process this negative information is critical in terms of its impact on their corporate associations. Corporate associations encompass all the information and beliefs that a person holds in reference to a particular company (Brown and Dacin 1997; see also Brown, Dacin, Pratt, and Whetten 2006 [this issue]). Because negative information is given greater weight compared with equally extreme positive information (e.g., Herr, Kardes, and Kim 1991; Klein and Dawar 2004), negative information is likely to exert a strong, negative impact on the formation of corporate associations. Therefore, it is reasonable to fear that negative publicity about a company or its products will result in negative corporate associations. Such negative associations are likely to negatively influence consumers' behavior toward the company and its products and thereby negatively affect sales, profits, and stock price. 
However, there are instances in which negative publicity seems to have little effect on companies. For example, after the Mercedes-Benz A-Class rolled over in 1997 during the so-called elk test (devised to assess a car's ability to swerve around obstacles in an emergency), the prestigious car brand was not lastingly affected. The company's reputation-that is, the mental associations about the organization held by others outside the organization (Brown et al. 2006) - was seemingly protected. This relative immunity to negative publicity may be due to consumers' relationships with the company as a brand. One recently introduced factor that has been found to moderate the impact of negative publicity is the degree of commitment to a brand under attack (Ahluwalia, Burnkrant, and Unnava 2000). Ahluwalia et al. (2000) showed that when consumers are highly committed to a brand, they might dismiss negative publicity by processing the information in a biased manner.

The present research builds on that of Ahluwalia et al. (2000) in two important ways. First, we show that the effect of negative information on attitudes and behavioral intentions is moderated by consumers' identification with a company. Empirical results indicate that commitment is likely to be one outcome of the higher order psychological construct of identification (Bergami and Bagozzi 2000; Brown, Barry, Dacin, and Gunst 2005). Second, we demonstrate a boundary condition, in that when information becomes extremely negative, identification no longer moderates the effect.

Whereas commitment relates to a desire to maintain a good relationship, possibly resulting in loyalty to a brand (e.g., Moorman, Zaltman, and Deshpande 1992; Brown et al. 2005), the higher order construct of consumercompany identification is the extent to which aspects of an organization's identity overlap with consumers' identities. Identified consumers are motivated to maintain untainted associations with a company as a means of preserving the company as a source of positive identity and self-esteem. If the source of identification (i.e., the company) is attacked, the attack can affect the self-esteem of those who identify with it. Such an attack can result in a defensive reaction. When faced with negative information, identification can lead to attitudinal commitment as well as behaviors such as purchase and declarations of brand loyalty as defensive reactions. Thus, consistent with Brown et al. (2005), we argue that identification is a more primary representation of a consumer's relationship with a company or brand than commitment and that it is the more proximal cause of motivated reasoning. Therefore, our research concentrates on the effects of consumer-company identification on corporate associations and behavioral intentions in the context of negative publicity.

We posit that consumers who strongly identify with a company are likely to be motivated to maintain their positive corporate associations and to dismiss negative infor- mation as much as possible. Weakly identified consumers, in comparison, are more likely to incorporate negative publicity into their corporate associations. Although we hypothesize that strong customer-company identification can insulate a company from the effects of negative publicity, as Ahluwalia et al. (2000) did for commitment, we suggest that this buffering effect disappears when the information is extremely negative. Even strongly identified consumers are not likely to maintain positive views of a company when the information about it is extremely negative (Bhattacharya and Sen 2003). Consequently, they will exhibit negative corporate associations and potentially unfavorable behaviors toward the company, as do those who are weakly identified. Strong identifiers should reach a point at which "enough is enough," and identification no longer mitigates the detrimental effects of negative information. We explain the immunizing effect of consumercompany identification against the impact of moderately negative publicity, as well as its boundary condition in case of extremely negative information, in terms of motivated reasoning theory (e.g., Kunda 1990).

\section{CONCEPTUAL FOUNDATION AND HYPOTHESES}

\section{Consumer-Company Identification}

Identification with social entities plays an important role when it comes to the development of a person's social identity (e.g., Tajfel and Turner 1985), and individuals develop social identities by establishing cognitive links between themselves and social groups or organizations. Bhattacharya and Sen (2003) argued that individuals' identification with a company can be very powerful even without their formal membership. The authors suggested that consumer-company identification is "the primary psychological substrate for the kind of deep, committed, and meaningful relationships that marketers are increasingly seeking to build with their customers" (p. 76).

Similarly, organizational identification has been described as the degree to which individuals feel a sense of connectedness to an organization (Mael and Ashforth 1992) and define themselves by the same attributes they believe define the organization (Dutton, Dukerich, and Harquail 1994). If these beliefs about an organization become self-referential or self-defining for a person, he or she is said to identify with the entity (Pratt 1998). Drawing on these definitions, we define consumer-company identification as the degree to which consumers feel a sense of connection to a company and the degree to which aspects of the perceived organizational identity are self-referential and self-defining for them.

Although identification develops and grows over time, a person can identify with a company or organization that 
is yet unknown to him or her, if the consumer and the organization share the same values. For example, a person who holds strong values about environmental protection might feel an instant sense of connection and identification with an organization that holds these common values, once he or she becomes aware of that company.

If a consumer identifies with a company, he or she is likely to have positive thoughts and feelings about it. This implies that the identified consumer's corporate associations are favorable. We agree with the extant research indicating that identification with a company also results in a commitment to it (Bergami and Bagozzi 2000; Brown et al. 2005), implying attitude strength, loyal behavior, and repeat buying. Attitudinal and behavioral commitment represent likely outcomes of identification and would be likely to reinforce the strength of identification. However, behavioral commitment may also be affected by external factors, such as the availability of substitutes, without necessarily requiring identification with the company.

When strongly identified consumers' positive beliefs about a company are challenged by negative information, they are likely to try to protect and preserve those beliefs. However, this immunizing effect of identification against negative information should reach its limits when the degree of negativity increases (Bhattacharya and Sen 2003). Specifically, strongly identified customers tolerate corporate failures or misbehavior up to a certain point, through their motivation to maintain a positive view of the company. However, if the reported instances are just too negative, a breaking point will be reached at which the company can no longer serve as a source of positive social identity. Motivated reasoning theory sheds light on the potential effects of identification on the perception and processing of negative information about the company.

\section{Motivated Reasoning and the Impact of Negative Information}

According to motivated reasoning theory (e.g., Kunda 1990), people are driven by two major sets of goals when processing information and forming judgments. They can be motivated either to arrive at an accurate conclusion or to arrive at a particular desired conclusion (Chaiken, GinerSorolla, and Chen 1996; Kunda 1990). Research on motivated reasoning suggests that when there is a strong motivation to reach a particular conclusion, individuals' evaluations of information as well as perceptions about themselves and others can be dramatically biased (e.g., Boiney, Kennedy, and Nye 1997; Kunda 1990). When motivated by accuracy, individuals have the desire to form correct judgments and to process information in an unbiased fashion.

Strong consumer-company identification should evoke the motivation to protect self-defining beliefs and the meaning derived from a relationship with a company. Strongly identified consumers should engage in defensive information processing with a bias in the direction of their preferred conclusions (Eagly and Chaiken 1993). For example, if a baseball fan who strongly identifies with the New York Yankees were to read an unfavorable newspaper article about the team, he would likely be biased in processing the information such that he can arrive at a positive conclusion. This biased directional processing would protect existing self-defining beliefs, since changing those beliefs and attitude would be threatening to his overall identity, of which being a Yankee fanatic is an essential part.

Weakly identified consumers, on the contrary, who do not see a company as important to their senses of self and whose beliefs about the company are not as strongly selfdefining, should be guided by the motivation to form accurate judgments. When motivated by accuracy concerns, the weight given to negative information is enhanced (Ahluwalia 2002). Therefore, consumers' attitudes toward the company should be more easily swayed and should decline consistent with the degree of negativity of the incoming information. Thus, we hypothesized that perceptions of information about a company will show a main effect of identification, with information perceived as more positive by those more strongly identified with the company:
Hypothesis 1: When exposed to information about a company, consumers who strongly identify with the company will perceive that information to be more favorable than those who weakly identify with the company.

However, it has been argued that motivated reasoning is not unconstrained. Kunda (1990) proposed that people motivated to arrive at a particular conclusion attempt to be rational and that they draw the desired conclusion only if they can summon up the evidence necessary to support it. Extremely negative information has been shown to be highly diagnostic (Herr et al. 1991), and it might thus be impossible to ignore even if a person would like to do so. It might also be so extreme that reducing the weight given to the negative attribute, which is one strategy to protect the overall evaluation (Ahluwalia 2000), does not prevent a negative evaluation. Therefore, while strongly identified consumers will refute undesirable evidence if they can, information that is extremely negative has to be incorporated into impressions and attitudes (Lord, Ross, and Lepper 1979). That is, the difficulty of using a defensive or directional motivation to reach a desired conclusion is increased relative to the degree to which the information contradicts that conclusion. As Bhattacharya and Sen (2003) suggested, we can expect that when information is extremely negative, it exceeds even strong identifiers' levels of tolerance.

Because of motivated reasoning, consumers who receive information about a company with which they strongly 
identify should process that information in a biased and defensive fashion. Therefore, the valence of the thoughts strong identifiers generate while processing moderately negative information should be more positive than the thoughts of weak identifiers. However, on the basis of the boundaries of motivated reasoning, we do not expect to find this bias in thoughts generated by strong identifiers when information is extremely negative. Consequently, thoughts should be equally negative for strong and weak identifiers when the information given is extremely negative. These thoughts are indicative of the process of reasoning that results in the effects on reported attitudes and behavioral intentions toward a company.

Thus, motivated reasoning inspired by strong identification is expected to influence consumers' attitudes toward a company as well as their behavioral intentions to purchase the company's product(s). Consumers' levels of identification with the company should affect their responses to moderately negative information. However, when extremely negative information overwhelms the defenses of strongly identified consumers, attitudes and behavioral intentions should not differ on the basis of the level of identification. Hence, we hypothesized an interaction between identification and the degree of negativity of the information:

Hypothesis 2: When given moderately negative information, consumers who strongly identify with a company will exhibit more favorable attitudes and behavioral intentions than those who weakly identify with the company. When given extremely negative information, attitudes and behavioral intentions will not vary between weak and strong identifiers.

\section{METHOD}

The hypotheses were tested using a 3 (information valence: neutral, moderately negative, extremely negative) $\times$ 2 (identification: weak, strong) full-factorial, betweensubjects design. Information valence was manipulated, and consumer-company identification was measured.

Research participants were 210 shoppers recruited at a San Diego mall who were randomly assigned to one of the experimental conditions. Forty-six percent of those who were approached agreed to participate. Respondents were informed that they were participating in a market survey that examined how people evaluate investment options. Of the 210 participants, $45 \%$ were current stock, bond, or mutual fund owners. Twenty-five percent considered themselves just as knowledgeable about mutual fund investing as the general population; $41 \%$ perceived themselves as less knowledgeable ( $34 \%$ felt more knowledgeable) than others in this regard.
All participants were told to imagine that they had inherited $\$ 50,000$ from a relative and that the money was currently invested in mutual funds managed by the (fictitious) company Conscience Funds. This instruction was intended to increase participants' interest in the scenario and their potential for identification with the company. After this introduction, participants were asked to very carefully read a one-page flier from the company that described its strongly held corporate values in social responsibility and its policy to create mutual funds that invest in companies meeting screening requirements for social responsibility. It read,

Conscience Funds enables investors to align their financial goals with their personal values through a selection of professionally managed socially responsible mutual funds. By screening companies not only by their investment potential but also by standards of social responsibility, Conscience Funds challenges companies to reach for a higher "bottom line" and offers investors the opportunity to do good while doing well.

In the flyer, participants were further informed that Conscious Funds invested in companies that provide goods and services that improve the quality of life and societal welfare.

The description of the company was expected to result in strong identification for about half of the research population. A pretest indicated that approximately half of the participants were likely to identify with the socially responsible investment company. For these individuals, social responsibility is likely to be part of their value systems and important to their senses of self, and they should be more inclined to identify with the investment company because the social responsibility aspects of the organizational identity overlapped with their own identities. The other half of the participants, for whom social responsibility was likely to be less important to their self-concepts, were likely to more weakly identify with Conscience Funds.

After reading the company's flier, participants answered an eight-item measure of the strength of their identification with the company. Five items served to measure consumers' senses of connection and self-categorization with the company ("I am somewhat associated with Conscience Funds," "I have a sense of connection with Conscience Funds," "I consider myself as belonging to the group of people who are in favor of Conscience Funds," "Customers of Conscience Funds are probably similar to me," and "Employees of Conscience Funds are probably similar to me"). Three items measured the perceived overlap in beliefs with the investment fund and to what extent this was self-referential for participants ("Conscience Funds shares my values," "Being a customer of Conscience 
Funds is part of my sense of who I am," and "Purchasing Conscience Funds' mutual funds would help me express my identity"). All identification items were measured on 9-point scales on which higher values indicated stronger degrees of identification. Principal components analysis showed that all eight items loaded on a single factor that explained $66 \%$ of the total variance $(\alpha=.92) .{ }^{2} \mathrm{~A}$ median split (median $=5.50$ ) resulted in 104 weaker identifiers $\left(M_{\mathrm{IW}}=3.63\right)$ and 106 stronger identifiers $\left(M_{\mathrm{ls}}=6.79\right)$.

We also measured participants' social responsibility values through the use of three questions (e.g., "It is extremely important to me that companies behave responsibly when it comes to social and environmental matters"). As expected, participants' identification with Conscience Funds was significantly correlated with the extent to which they endorsed these values $(r=.57, p<.01)$.

After participants completed the identification measures and reported their social responsibility values, they received a fictitious newspaper article that had allegedly recently appeared in the Wall Street Journal. Depending on assigned condition, a neutral, moderately negative, or extremely negative newspaper article was presented to participants after they had returned the initial portion of the survey. The story contained information about an alleged annual ranking of mutual funds' earnings. We chose to manipulate information about financial performance because it is considered one of the central dimensions of corporate reputation (Fombrun, Gardberg, and Sever 2000) and because it is likely to be seen as independent of social responsibility. In the neutral story, the reader learned that the earnings of Conscious Funds were average, the company had finished 82nd among a total of 163 funds analyzed, and analysts advised holding shares. The moderately negative story reported on relatively poor earnings of Conscious Funds, which finished worse than average at 117 th, and analysts advised to consider selling shares. The extremely negative story read that Conscious Funds finished dead last, because the funds were losing investors' money, and analysts advised to immediately sell shares.

The three different articles were pretested on a university student population to determine whether they were perceived as significantly different in valence from one another. Thirty-four subjects were exposed to one of the three articles. They then completed a four-item measure of favorability in terms of how the articles depicted the company (e.g., poor performance or excellent performance, unfavorable or favorable; rated on 11-point scales from -5 to +5 ). Perceptions of the negativity of the depiction of the company in the fictitious news stories significantly differed overall and from one another, $M_{\text {neut }}=0.96, M_{\text {mod neg }}=$ $-2.71, M_{\text {ext neg }}=-3.89, F(2,99)=112.12, p<.01$, indicating that the manipulation of information valence was successful. The results from the main study, furthermore, showed that the articles did not vary in terms of the ratings of their comprehensibility, $F(2,207)=1.88, p>.10$, or believability, $F(2,207)=0.03, p>.10$.

Following exposure to the newspaper article, participants were first asked to list all their thoughts while reading the stories (Petty and Cacioppo 1977). They were given 3 minutes to complete the thought listing. The total number and valence of thoughts were coded by two independent judges. There was a $73 \%$ agreement between the two judges. Disagreements were resolved through discussion, and for the few statements for which discussion was not fruitful, one of the authors was called in to break the tie. A thought valence index was constructed by subtracting the number of negative from the number of positive thoughts.

We measured people's behavioral intentions on the basis of their agreement with three statements ("Would you keep your $\$ 50,000$ inheritance invested in Conscience Mutual Funds?" "How likely would you be to invest additional money in Conscience Funds, if you had more money to invest?" and "If a friend asked you for advice about investments, how likely would it be that you recommended Conscious Funds to him or her?" on scales ranging from 1 to 9, combined into an average index: $\alpha=.94$ ). Attitude toward the company was measured using three 11-point semantic differential scales asking participants to describe their feelings toward the company (negative or positive, bad or good, unfavorable or favorable; scales ranged from -5 to +5 ; average index: $\alpha=.98$ ). Participants were then asked to indicate how they perceived the company to be depicted in the article (poor performance or excellent performance, negative or positive, bad or good, unfavorable or favorable; scales ranged from -5 to +5 ; average index: $\alpha=.97$ ). Finally, participants were asked whether they currently invested in stocks, bonds, or mutual funds and how knowledgeable they were about mutual fund investment. They were then debriefed and paid a small compensation of $\$ 5$.

\section{RESULTS}

The data were analyzed using analysis of variance (ANOVA) with the level of identification (on the basis of the median split) and information valence as independent variables (see Table 1 for summary results). In addition, the data were analyzed using regression with identification as a continuous variable to provide further evidence that the strength of identification leads to the predicted effects. The control variables, current stock ownership and perceived knowledge of mutual fund investing were not significant covariates in any of the analyses.

Perceptions of how the article depicted the company revealed a significant main effect of information valence, $F(2,204)=62.27, p<.01$, indicating that the manipulation was successful. There was also a significant main effect of 
TABLE 1

Analysis of Variance Results

\begin{tabular}{lcccc}
\hline & & \multicolumn{2}{c}{ Dependent Variable } \\
\cline { 2 - 5 } $\begin{array}{l}\text { Independent } \\
\text { Variable }\end{array}$ & $\begin{array}{c}\text { Investment } \\
\text { Intentions }\end{array}$ & $\begin{array}{c}\text { Attitude Toward } \\
\text { the Company }\end{array}$ & $\begin{array}{c}\text { Perceptions of Information } \\
\text { About the Company }\end{array}$ & Thought Valence \\
\hline Information valence & $F(2,204)=55.03, p<.01$ & $F(2,204)=55.27, p<.01$ & $F(2,204)=62.27, p<.01$ & $F(2,204)=29.95, p<.01$ \\
Identification & $F(1,204)=23.91, p<.01$ & $F(1,204)=23.59, p<.01$ & $F(1,204)=14.96, p<.01$ & $F(1,204)=6.68, p<.01$ \\
Interaction (Information & $F(2,204)=4.15, p<.05$ & $F(2,204)=3.74, p<.05$ & $F(2,204)=3.69, p<.05$ & $F(2,204)=3.24, p<.05$ \\
$\quad$ & & & & \\
\hline
\end{tabular}

identification, in support of Hypothesis 1. Across valence conditions, strong identification with the company led to a more positive perception of the article than weak identification, $M_{\mathrm{Is}}=-0.89, M_{\mathrm{Iw}}=-1.87, F(1,204)=14.96, p<.01$. The thought listings provided additional support for Hypothesis 1 on the basis of the predicted effect of motivated reasoning. The results for thought valence (the number of positive minus negative thoughts) indicated that identification affected the content of participants' thoughts. Strongly identified participants had significantly more positive thoughts than those in the weak identification condition, $M_{\mathrm{Is}}=-0.65, M_{\mathrm{Iw}}=-1.32, F(1,204)=6.68, p<$ .01. Regression analysis rendered the same main effects of identification (perception of article: $\alpha=.19, p<.01$; thought valence: $\alpha=.19, p<.01$ ).

It was clear that subjects' elicited thoughts showed evidence of the impact of identification on performance. For example, a strong identifier exposed to the moderately negative condition stated that the company did "stand by company policies despite poor performance. Good idea to stay with it if I want to support ethical companies." In contrast, a weak identifier exposed to the same condition said, "When most of the people lost money investing in the plan, I wouldn't care if it helped out the community."

As expected, ANOVA showed that those strongly identified with the company had significantly more positive behavioral intentions (i.e., investment and word of mouth) across valence conditions than those weakly identified, $M_{\mathrm{Is}}=4.25, M_{\mathrm{Iw}}=3.11, F(1,204)=23.91, p<.01$. Similar findings were observed for participants' attitudes toward the company. Strong identifiers had significantly more positive attitudes toward Conscience Funds than weak identifiers, $M_{\mathrm{Is}}=6.03, M_{\mathrm{Iw}}=4.54, F(1,204)=23.59, p<$ .01. Regression analysis also supported these main effects of identification (investment: $\alpha=.34, p<.01$; attitude: $\alpha=$ $.33, p<.01$ ).

In support of Hypothesis 2, and consistent with the contention that there are limits to motivated reasoning, there was an interaction effect between identification and information valence. Strong identification with the company was associated with more positive investment intentions in the face of moderately negative information, but not when that information was extremely negative (see Table 2). The interaction of identification and information valence was a significant predictor of investment intentions, $F(2,204)=$ $4.15, p<.05$. Regression analysis, with identification as a continuous variable, also indicated a significant interaction effect $(\alpha=-.47, p<.01)$. Planned comparisons indicated that the pattern of means was as predicted by Hypothesis 2. When participants were given neutral information, those who more strongly identified with the company were more willing to invest in the company's mutual funds than those who were more weakly identified, $M_{\mathrm{Is}}=$ 6.42 versus $M_{\mathrm{Iw}}=4.16$, respectively; $t(68)=4.68, p<.01$. This trend was also true for moderately negative information. Strongly identified consumers were more willing to invest in the mutual funds given moderately negative information than weak identifiers, $M_{\mathrm{Is}}=4.27$ versus $M_{\mathrm{Iw}}=$ 3.32 , respectively; $t(68)=2.03, p<.05$. When given extremely negative information, more strongly identified consumers' willingness to invest dropped to the same level as that of weakly identified consumers, $M_{\mathrm{Is}}=2.29$ versus $M_{\mathrm{Iw}}=1.74, p>.10$.

As predicted, the interaction of identification and information valence was also a significant predictor of attitudes toward the company, $F(2,204)=3.74, p<.05$. Regression analysis showed the same interaction effect $(\alpha=-.36, p<$ .05 ). Given neutral information, strong identifiers had significantly more positive attitudes toward the company than weak identifiers, $M_{\mathrm{Is}}=8.48$ versus $M_{\mathrm{Iw}}=5.78$, respectively; $t(68)=4.78, p<.01$. When information about the company was moderately negative, strong identifiers still had significantly more positive attitudes than weak identifiers, $M_{\mathrm{Is}}=6.65$ versus $M_{\mathrm{IW}}=4.99$, respectively; $t(68)=$ $2.74, p<.01$. However, when information was extremely negative, strong identifiers' attitudes were not significantly more positive than weak identifiers' attitudes, $M_{\mathrm{Is}}=$ 3.19 versus $M_{\mathrm{IW}}=2.72, p>.10$.

These results suggest that motivated reasoning is responsible for the effect of strong identification, depending on the degree of negative information given to consumers. Mediational analyses were also conducted for perceptions of the article and for the thought listing measure. Those analyses provided further support for the contention that the effects reported above are due to the extent to which information processing is biased by identification. 
TABLE 2

Means and Standard Deviations (in parentheses) of Dependent Variables

\begin{tabular}{|c|c|c|c|}
\hline \multirow[b]{2}{*}{ Dependent Variable } & \multicolumn{3}{|c|}{ Information Valence } \\
\hline & Neutral & Moderately Negative & Extremely Negative \\
\hline \multicolumn{4}{|l|}{ Investment intentions } \\
\hline Weak identifiers & $4.16(2.35)$ & $3.33(1.84)$ & $1.74(1.10)$ \\
\hline Strong identifiers & $6.42(1.53)$ & $4.27(2.01)$ & $2.29(1.89)$ \\
\hline \multicolumn{4}{|c|}{ Attitude toward the company } \\
\hline Weak identifiers & $5.78(2.81)$ & $4.99(2.26)$ & $2.72(2.12)$ \\
\hline Strong identifiers & $8.48(1.64)$ & $6.65(2.73)$ & $3.19(2.47)$ \\
\hline \multicolumn{4}{|c|}{ Perceptions of information about the company } \\
\hline Weak identifiers & $0.03(2.80)$ & $-2.35(2.43)$ & $-3.55(1.88)$ \\
\hline Strong identifiers & $2.34(1.73)$ & $-1.25(2.62)$ & $-3.39(2.28)$ \\
\hline
\end{tabular}

The analyses on article perception as a potential mediator rendered identification as a significant predictor of article perception $(\alpha=.19, p<.01)$ and attitude $(\alpha=.30, p<$ $.01)$ as well as intention to invest $(\alpha=.30, p<.01)$. Furthermore, including article perception in the regression equation attenuated the relationship between identification and attitude (to $\alpha=.17, p<.01$ ) and investment intention (to $\alpha=.17, p<.01$ ), whereas the effect of article perception on attitude and investment intention was significant (both $\alpha$ values $=.69, p<.01$ ). Although the relationship between identification and attitude and investment intention was not reduced to insignificance, the Sobel test of mediation (Preacher and Leonardelli 2001) rendered significant results, indicating partial mediation by the perception of the article (for attitude as dependent variable: $z=2.76, p<.01$; for investment intention as dependent variable: $z=2.75, p<.01$ ).

Similar results emerged for thought valence as a potential mediator. Identification significantly predicted thought valence $(\alpha=.17, p<.05)$. It also significantly predicted attitude $(\alpha=.30, p<.01)$ as well as investment intentions $(\alpha=.30, p<.01)$. Furthermore, including thought valence in the regression equation attenuated the impact of identification on attitude $(\alpha=.22, p<.01)$ as well as investment intention $(\alpha=.22, p<.01)$. Thought valence was a significant predictor for attitude $(\alpha=.46, p<$ $.01)$ and investment intention $(\alpha=.50, p<.01)$. Sobel's test of mediation was again significant (for attitude as dependent variable: $z=2.76, p<.01$; for investment intentions as dependent variable: $z=2.68, p<.01$ ), indicating partial mediation by thought valence.

\section{DISCUSSION AND CONCLUSION}

Our research has important implications for companies in today's business world. The findings suggest that a company can pursue a strategy to protect itself from the impact of negative information before such information arrives, as long as the negativity of the information is not too extreme. That is, creating a situation or undertaking a focused strategy to encourage strong identification with the company may serve to protect consumers from the impact of moderately negative information. However, companies have to be aware that the buffering effect of identification has its limits when the news is extremely negative. There comes a point at which enough is enough, and the strongly identified show negative corporate associations and behavioral intentions just as do the weakly identified.

Interestingly, this finding is consistent with the research in social psychology and marketing on contrast effects emerging when product performance falls significantly below inflated expectations. A point is reached at which the resulting evaluation is lower than if no expectations were initially created (Anderson 1973; Sherif and Hovland 1961). The point at which contrast occurs has been hypothesized to be a function of the strength of expectations and of the discrepancy between expectation and performance (Woodruff, Cadotte, and Jenkins 1983). In the context presented here, consumer-company identification is similar to the strength of expectations, and the expectation-performance discrepancy is similar to the extent to which a company falls from grace. Although positive expectations and identification can backfire, these factors are generally positive influences on reactions to a company.

A good strategy to engender identification is to highlight those aspects of the organizational identity that appeal to consumers' and stakeholders' values and beliefs when defining the intended image. The present study showed that corporate social responsibility (CSR), which reflects an organization's activities with respect to its perceived societal obligations, can serve as a viable concept to enhance consumer identification, if the firm's target customers value social responsibility. Real-world companies such as Ben \& Jerry's and Tom's of Maine, for example, publicize their strong environmental stances, encouraging potential customers to purchase from the companies if they identify with those values. In a similar vein, Sears is 
sponsoring a television program on which the homes of disadvantaged citizens are "made over."

Klein and Dawar (2003) found that attributions of social responsibility mediate the impact of product-harm crises on consumers' brand evaluations. However, this mediation effect was found only in consumers who were CSR sensitive. We might speculate that those CSRsensitive participants identified with a brand that experienced a product crisis because they felt a sense of connection to the socially responsible company.

Emphasizing any other attribute or belief that is valued by a company's actual and/or potential customer base is also likely to create or strengthen consumer-company identification. General Motors, for example, stresses its country of origin and belief in patriotism, which may enhance the identification of American consumers who also feel strongly about their country. The sense of connection element in identification can furthermore be encouraged through marketing approaches such as frequent-flyer programs or supermarket "clubs." Clearly, any strategy that can encourage identification with a firm before the potentially inevitable onslaught of negative information is more valuable than a strategy implemented after the fact.

Our research findings suggest another possible consequence of identification. Strongly identified consumers generated significantly more positive than negative thoughts about the company than those who were weakly identified. In addition, the strongly identified expressed a greater willingness to recommend the company than weakly identified consumers, even when exposed to moderately negative publicity. Thus, strengthening consumers' identification with a company is likely to favorably influence informal "word-of-mouth" communication about the company (Brown et al. 2005). In the case of negative information, we can speculate that those strongly identified might engage in more positive word-of-mouth behavior to defend their senses of self. However, this should be the case only if the information is moderately negative and defensive processing takes place. When the information reaches a high level of negativity, however, we do not expect those who strongly identify with the company to express positive word-of-mouth, just as they do not exhibit more positive attitudes or behavioral intentions than those weakly identified. What might happen instead is that the attention-getting nature of negative information engenders more negative word-of-mouth behavior, thereby hurting the reputation of the company. Future research should investigate the effect of identification on word-of-mouth communications when consumers are faced with varying degrees of negative information about companies.

While the present study observed that identification loses its buffering effect under extremely negative conditions, we expect that strong identification might lead to more negative corporate associations than weak identifi- cation under certain conditions of moderate negative publicity. While in this research, we studied negative information that does not directly attack the basis of consumer identification (self-defining beliefs concerning social responsibility), information that does attack the basis of consumer identification may not need to be as negative to have a dramatic effect on identifiers. That is, with negative information that directly attacks their self-defining beliefs, contrast might occur in response to less extreme negative publicity for those who strongly identify with an organization, because the basis for identification and thereby an aspect of consumers' self-concepts is under attack. Hence, even moderately negative information that is relevant to the CSR dimension of a company's reputation might lead to more negative reactions by identifiers than nonidentifiers. This is a direction for future research.

Another fruitful area of research is if and how companies should react to negative publicity. The few empirical studies about the effectiveness of refutation strategies reported in the literature indicate mixed results. Research in the domain of rumors suggests that refuting a negative rumor about a firm may be counterproductive, because it serves to reintroduce the rumor in the process of discounting it (Tybout, Calder, and Sternthal 1981). However, it has been found that a focused approach to refutation, depending on consumers' levels of commitment with an entity, can be effective (Ahluwalia et al. 2000). That research found that for people who are strongly committed to a brand, compared with those weakly committed, a refutation is more effective when it reduces the value of the negative information (i.e., its diagnosticity) for discriminating between alternative brands. In comparison, for weakly committed consumers, a refutation based on counterarguing the negative information was relatively more effective.

Our study investigated consumers' reactions to only one incident of negative information. Since companies exist in a dynamic environment, it would be valuable to study how consumers process a stream of negative information about an entity and corresponding changes in identification and attitude over time. We believe that reinforced negativity about a company may serve to weaken identification, making a company ultimately more susceptible to the effects of negative information. Future research should examine these issues.

Future research should also examine the emotional aspect of consumer-company identification. In this research, we studied how the effect of negative information is moderated by the construct of consumer-company identification at a cognitive level. However, there is also likely to be an emotional component of the consumer-company relationship (Bergami and Bagozzi 2000). Strong identification occurs when a company becomes personally relevant for consumers, and personal relevance creates the potential for emotional reactions (Johnson and Stewart 2004). In fact, consumers' emotional attachment to a com- 
pany, which is likely to be concomitant with the more cognitive dimension of identification studied here, has been found to affect their attitudinal and behavioral commitment to the company and its products (Fedorikhin, Park, and Thomson 2005). Consumer-company identification and all its potential benefits and pitfalls clearly offer many intriguing avenues for future research.

\section{NOTES}

1. The authors are listed alphabetically.

2. The identification measure also correlated significantly with the visual identification scale developed by Bergami and Baggozi (2000) $(r=$ $.64, p<.01)$, suggesting convergent validity.

\section{REFERENCES}

Ahluwalia, Rohini. 2000. "Examination of Psychological Processes Underlying Resistance to Persuasion." Journal of Consumer Research 27 (September): 217-232.

- 2002. "How Prevalent Is the Negativity Effect in Consumer Environments?" Joumal of Consumer Research 29 (September): 270279.

__ Robert E. Burnkrant, and H. Rao Unnava. 2000. "Consumer Response to Negative Publicity: The Moderating Role of Commitment." Journal of Marketing Research 37 (May): 203-214.

Anderson, Rolphe E. 1973. "Consumer Dissatisfaction: The Effect of Disconfirmed Expectancy on Perceived Product Performance." Journal of Marketing Research 10 (February): 38-44.

Bergami, Massimo and Richard P. Bagozzi. 2000. "Self-Categorization, Affective Commitment and Group Self-Esteem as Distinct Aspects of Social Identity in the Organization." British Journal of Social Psychology 39 (4): 555-577.

Bhattacharya, C. B. and Sankar Sen. 2003. "Consumer-Company Identification: A Framework for Understanding Consumers' Relationships with Companies." Joumal of Marketing 67 (April): 76-88.

Boiney, Lindsley G., Jane Kennedy, and Peter Nye. 1997. "Instrumental Bias in Motivated Reasoning: More When More Is Needed." Organizational Behavior and Human Decision Processes 72 (1): 1-24.

Brown, Tom J., Thomas E. Barry, Peter A. Dacin, and Richard F. Gunst. 2005. "Spreading the Word: Investigating Antecedents of Consumers' Positive Word-of-Mouth Intentions and Behaviors in a Retailing Context." Journal of the Academy of Marketing Science 33 (2): 123138.

__ and Peter A. Dacin. 1997. "The Company and the Product: Corporate Associations and Consumer Product Responses." Journal of Marketing 61 (January): 68-84.

_- Michael G. Pratt, and David A. Whetten. 2006. "Identity, Intended Image, Construed Image, and Reputation: An Interdisciplinary Framework and Suggested Terminology." Journal of the Academy of Marketing Science 34(2): 99-106.

Chaiken, Shelly, Roger Giner-Sorolla, and Serena Chen. 1996. "Beyond Accuracy: Defense and Impression Motives in Heuristic and Systematic Processing." In The Psychology of Action: Linking Cognition and Motivation to Behavior. Eds. Peter M. Gollwitzer and John A. Bargh. New York: Guilford, 553-578.

Dutton, Jane E., Janet M. Dukerich, and C. V. Harquail. 1994. "Organizational Images and Member Identification." Administrative Science Quarterly 39 (34): 239-263.

Eagly, Alice H. and Shelley Chaiken. 1993. The Psychology of Attitudes. Fort Worth, TX: Harcourt Brace Jovanovich.

Fedorikhin, Alexander, C. Whan Park, and Matthew Thomson. 2005. "Fitting in With the Family: The Effect of Emotional Attachment on Consumer Responses to Brand Extensions." Working Paper. Kelley School of Business, Indiana University.
Fombnun, Charles, Naomi Gardberg, and Joy Sever. 2000. "The Reputation Quotient. A Multi-Stakeholder Measure of Corporate Reputation." Journal of Brand Management 7 (4): 241-255.

Herr, Paul M., Frank R. Kardes, and Jaewoo J. Kim. 1991. "Effects of Word-of-Mouth and Product Attribute Information on Persuasion: An Accessibility-Diagnosticity Perspective." Journal of Consumer Research 14 (4): 353-362.

Institute for Crisis Management. 2004. "Crisis Reports 2000-2003." Retrieved January 16, 2005, from http://www.crisisexperts.com

Johnson, Allison R. and David W. Stewart. 2004. "A Re-Appraisal of the Role of Emotion in Consumer Behavior: Traditional and Contemporary Approaches." In Review of Marketing Research, Vol. 1. Ed. N. Malhotra. Armonk, NY: M. E. Sharpe, 3-33.

Klein, Jill and Niraj Dawar. 2004. "Corporate Social Responsibility and Consumers' Attributions and Brand Evaluations in a Product-Harm Crisis." International Journal of Research in Marketing 21:203-217.

Kunda, Ziva. 1990. "The Case for Motivated Reasoning." Psychological Bulletin 108 (3): 480-498.

Lord, Charles G., Lee Ross, and Mark R. Lepper. 1979. "Biased Assimilation and Attitude Polarization: The Effects of Prior Theories on Subsequently Considered Evidence." Journal of Personality and Social Psychology 37:2098-2109.

Mael, Fred, and Blake E. Ashforth. 1992. "Alumni and Their Alma Mater: A Partial Test of the Reformulated Model of Organizational Identification." Journal of Organizational Behavior 13 (2): 103-123.

Moorman, Christine, Gerald Zaltman, and Rohit Deshpande. 1992. "Relationships Between Providers and Users of Market Research: The Dynamics of Trust Within and Between Organizations." Journal of Marketing Research 29 (August): 314-328.

Petty, Richard E. and John T. Cacioppo. 1977. "Forewarning, Cognitive Responding, and Resistance to Persuasion." Journal of Personality and Social Psychology 35 (9): 645-655.

Pratt, Michael G. 1998. "To Be or Not to Be: Central Questions in Organizational Identification." In Identity in Organizations: Building Theory Through Conversations. Eds. David A. Whetten and P. C. Godfrey. Thousand Oaks, CA: Sage, 171-207.

Preacher, Kristopher J. and Geoffrey J. Leonardelli. 2001. "Calculation for the Sobel Test: An Interactive Calculation Tool for Mediation Tests" [Computer software]. Available at http://www.unc.edu/ - preacher/sobel/sobel.htm

Sherif, Muzafer and Carl I. Hovland. 1961. Social Judgment: Assimilation and Contrast Effects in Communication and Attitude Change. New Haven, CT: Yale University Press.

Tajfel, Henri and John C. Tumer. 1985. Psychology of Intergroup Relations. Chicago: Nelson-Hall.

Tybout, Alice M., Bobby J. Calder, and Brian Sternthal. 1981. "Using Information Processing Theories to Design Marketing Strategies." Journal of Marketing Research 18 (February): 73-79.

Woodruff, Robert B., Ernest N. Cadotte, and Roger L. Jenkins. 1983. "Modeling Consumer Satisfaction Processes Using Experience Based Norms." Joumal of Marketing Research 20 (August): 296-304.

\section{ABOUT THE AUTHORS}

Sabine A. Einwiller (sabine.einwiller@fhso.ch) is a lecturer and researcher at the University of Applied Sciences Northwestern Switzerland. She worked on this research as a visiting scholar at the University of Southern California, visiting from the University of St. Gallen, Switzerland, where she received her Ph.D. She has published in journals such as the Journal of Consumer Psychology and the Personality and Social Psychology Bulletin. Her research interests include causes and the measurement of corporate reputation and stakeholder-company identification.

Alexander Fedorikhin (sfedorik@iupui.edu) is an associate professor in the Kelley School of Business at Indiana University. His research focuses on the intersection of affect and cognition in consumer decision making. He has published in such journals as 
the Journal of Consumer Research, the Journal of Consumer Psychology, and Organizational Behavior and Human Decision Processes.

Allison R. Johnson (ajohnson@business.queensu.ca) is an assistant professor of marketing in Queen's School of Business, Queen's University. She received her Ph.D. from the Marshall School of Business, University of Southern California. Her research interests include corporate social responsibility, customercompany identification, and consumer emotion.
Michael A. Kamins (mkamins@marshall.usc.edu) is an associate professor at the University of Southern California, Marshall School of Business. Dr. Kamins's current research interests lie in pricing strategy in the context of online auctions as well as in the impact of color on consumers' perceptions of products. He has published over 40 academic articles and proceedings in major academic journals, including the Journal of Marketing, the Journal of Marketing Research, the Journal of Consumer Research, the Journal of Consumer Psychology, the Journal of Advertising, and the Journal of Advertising Research. 